\title{
Effect of Carbon Monoxide on Dopamine and Glutamate Uptake and cGMP Levels in Rat Brain
}

\author{
Dilek Taskiran', Fatma Z Kutay and Sakire Pogun*,' \\ 'Department of Physiology, Ege University Center for Brain Research and School of Medicine, Turkey; ${ }^{2}$ Department of Biochemistry, Ege \\ University Center for Brain Research and School of Medicine, Turkey
}

\begin{abstract}
After the recognition of nitric oxide (NO) as a messenger molecule in the nervous system, carbon monoxide (CO) has received attention with similar properties. The present study aims to elucidate the effects of $\mathrm{CO}$ on synaptosomal dopamine $\left({ }^{3} \mathrm{H}\right.$-DA $)$ and glutamate $\left({ }^{3} \mathrm{H}-\mathrm{Glu}\right)$ uptake and on cGMP levels; possible interaction between $\mathrm{NO}$ and $\mathrm{CO}$ systems was also evaluated. Our results provide evidence for the inhibition of DA and Glu uptake by $\mathrm{CO}$ in a time-, dose-, and temperature-dependent manner in rat striatum and hippocampus, respectively; the inhibition observed was sexually dimorphic with more pronounced effects in females. Basal cGMP levels were higher in female rats than males in the striatum and exogenous CO increased striatal cGMP levels only in males; no effect of CO was observed in the hippocampus. In vivo nitric oxide synthase (NOS) inhibition increased DA and Glu uptake; however, CO was still effective in inhibiting uptake following NOS inhibiton. Taken together, these findings suggest a role for CO in trans-synaptic regulation through modulation of DA and Glu transporters and of cGMP levels; the effect on cGMP levels is independent of NOS activity and appears to be sexually dimorphic and region specific.

Neuropsychopharmacology (2003) 28, I I76-I I 8I, advance online publication, 9 April 2003; doi:I0. I038/sj.npp. I 300 I 32
\end{abstract}

Keywords: carbon monoxide; nitric oxide; dopamine; glutamate; transporter

\section{INTRODUCTION}

Carbon monoxide (CO) is endogenously produced by the microsomal enzyme heme oxygenase (HO; EC 1. 14.99.3), which cleaves heme to $\mathrm{CO}$, biliverdin, and iron. Molecular characterization of $\mathrm{HO}$ revealed the existence of three distinct forms of HO designated as HO-1, HO-2, and HO-3 (Kutty and Maines, 1981, 1982; Maines, 1988, 1997; Galbraith, 1999; Johnson and Johnson, 2000). The most striking difference between HO-1 and HO-2 is that HO-1 is a heat shock protein (HSP32) and inducible by a variety of agents, whereas HO-2 is constitutively expressed. Body distribution of HO-1 and HO-2 are also different: high levels of HO- 1 activity are seen in spleen and liver, and of HO-2 in brain and testis (Maines, 1988, 1997; Ewing and Maines, 1997). HO-3 is a recently identified isoform and appeares to regulate heme-dependent genes (Magnusson et al, 2000). CO, like nitric oxide (NO), binds to the heme moeity of soluble guanylate cyclase (sGC) (Brune et al, 1990; Verma et al, 1993; Ingi et al, 1996a; Snyder et al, 1998) and in cultured olfactory neurons HO inhibitors reduce cGMP levels (Ingi et al, 1996b). Cytochrome $c$ oxidase, the terminal enzyme in the

*Correspondence: Department of Physiology, Ege University School of Medicine, 35 I00 Bornova-Izmir, Turkey, Fax: +90 2323746597,

E-mail: pogun@med.ege.edu.tr

Received 12 August 2002; revised 03 December 2002; accepted 18 December 2002

Online publication: 20 December 2002 at http://www.acnp.org/ Citations/Npp 122002448 mitochondrial electron transport chain, is another potential target for the actions of CO in the cell (Piantadosi, 1996).

Several studies indicate the colocalization of HO-2 and nitric oxide synthase (NOS) in various neural and vascular tissues (Maines, 1997; Juckett et al, 1998; Snyder et al, 1998). CO binds to the heme moeity of NOS and changes the effects of NO depending on the concentration. Furthermore, higher concentrations of $\mathrm{CO}$ have been shown to increase peroxynitrite levels and induce oxidative stress (Ischiropoulos et al, 1996; Thom et al, 1997). Although direct evidence is missing, an interaction between the $\mathrm{HO} / \mathrm{CO}$ and NOS/NO systems is plausible.

Neurotransmitter transporters, or reuptake carriers, terminate the action of released neurotransmitter by reuptake and play an important role in the regulation of synaptic transmission in neurons. While short-term modulation of transporters involves a direct effect, changes in gene expression are required for long-term modulation. Dopamine transporter (DAT) is closely related to serotonin and norepinephrine transporters and together they form a subfamily within the large family of $\mathrm{Na}^{+} / \mathrm{Cl}^{-}$-dependent transporters. DAT, a membrane-bound glycoprotein, is localized presynaptically and controls dopamine (DA) levels in the synaptic cleft by mediating uptake of released DA (Kuhar, 1997; Kuhar et al, 1999; Pogun, 1997). DAT plays a critical role in the regulation of cognitive functions and locomotor activity and it is a target for psychostimulant drugs including cocaine and amphetamine (Kuhar, 1997; Kuhar et al, 1999; Pogun, 1997). Glutamate (Glu) is a major 
excitatory amino-acid (EAA) neurotransmitter in the brain and high-affinity glutamate transporters (GLUT) are thought to be essential for terminating synaptic transmission as well as for maintaining the extracellular Glu concentration below toxic levels (Tanaka, 2000).

The involvement of $\mathrm{NO}$ in a type of retrograde uptake regulation has been suggested. Pogun et al $(1994 \mathrm{a}, \mathrm{b})$ have demonstrated the inhibition of DA, Glu, and 5-HT uptake by NO in a dose-, time-, and temperature-dependent manner in synaptosomes prepared from the rat brain. In accordance with these in vitro findings, Koylu et al have shown an increase in DA and Glu uptake following systemic administration of $\mathrm{N}_{\mathrm{G}}$ Nitro-L-arginine (L-NA) (Koylu et al, 1998).

Since CO shares some of the chemical and biological properties of NO, it may also act as a neuromodulator in synaptic regulation. The aim of this study was to evaluate the effect of CO treatment on DA and Glu uptake in synaptosomes prepared from male and female rat brains. In order to examine the effect of exogenously applied CO on NOS and guanylate cyclase, and to elucidate the possible mediation of cGMP and/or NO in the effects of CO on uptake, we also determined cGMP levels and the stable end products of NO $\left(\mathrm{NO}_{2}^{-}+\mathrm{NO}_{3}^{-}\right)$. To test the interaction between $\mathrm{CO}$ and $\mathrm{NO}$, ex vivo uptake experiments were performed, with or without $\mathrm{CO}$, in rats treated with systemic L-NA injections to inhibit NOS in vivo. Since the major aim of the study was to study the effect of CO on DA and Glu transport, we chose to do the assays in brain regions with high transporter expression, namely striatum for DA and hippocampus for Glu uptake.

\section{EXPERIMENTAL PROCEDURES}

\section{Animals}

A total of 34 male and eight female adult Sprague-Dawley rats $(250 \pm 40 \mathrm{~g})$, maintained on a $12: 12 \mathrm{~h}$ light : dark cycle with food and water provided ad libitum, were used for the assays. The protocol employed was approved by the Institutional Ethics Committee.

\section{Chemicals}

$\left[{ }^{3} \mathrm{H}\right]$-Glu and $\left[{ }^{3} \mathrm{H}\right]-\mathrm{DA}$ were purchased from Amersham. Nitrate reductase was obtained from Boehringer Mannheim. All other chemicals were obtained from Sigma.

\section{In Vivo NOS Inhibition}

Rats were injected with L-NA (50 mg/kg, i.p.) or saline and decapitated after $30 \mathrm{~min}$ (Koylu et al, 1998; Forman et al, 1998; Yilmaz et al, 2000). Corpus striata and hippocampi of control and NOS-inhibited rats were used for ex vivo DA and Glu uptake experiments, respectively.

\section{Tissue Preparation}

Rats were decapitated, brains rapidly removed and dissected (hippocampus and corpus striatum) on ice. $\left[{ }^{3} \mathrm{H}\right]$-Glu and $\left[{ }^{3} \mathrm{H}\right]-\mathrm{DA}$ uptake assays were carried out as previously described (Pogun et al, 1994a,b). Synaptosomes were prepared in $0.32 \mathrm{M}$ sucrose and a P2 pellet was obtained by centrifugation. The synaptosomes were resuspended in sucrose $(15 \mathrm{mg}$ original wet weight $/ \mathrm{ml}$ ) and aliquots were used in uptake experiments; the remaining tissue suspensions were stored at $-30^{\circ} \mathrm{C}$ for cGMP and $\mathrm{NO}_{2}^{-}+\mathrm{NO}_{3}^{-}$ determinations. To assess whether sex differences exist in the effect of $\mathrm{CO}$ on $\left[{ }^{3} \mathrm{H}\right]$-Glu and $\left[{ }^{3} \mathrm{H}\right]$-DA uptake, synaptosomes prepared from female rat brains were also used.

\section{Uptake Assays}

Uptake assays were carried out in modified Krebs-Ringer phosphate buffer $(126 \mathrm{mM} \mathrm{NaCl}, 4.8 \mathrm{mM} \mathrm{KCl}, 1.3 \mathrm{mM} \mathrm{CaCl}$, $1.4 \mathrm{mM} \mathrm{MgSO}$, $16.0 \mathrm{mM} \mathrm{Na}$ phosphate, $2 \mathrm{mg} / \mathrm{ml}$ dextrose, and $0.2 \mathrm{mg} / \mathrm{ml}$ ascorbic acid). Blank values were obtained by adding $1 \mathrm{mM}$ nomifensin and $10 \mathrm{mM}$ Glu for DA and Glu uptake, respectively. CO (99.99\%) was bubbled into synaptosomes for 1,5 , or $10 \mathrm{~min}$ at $37^{\circ} \mathrm{C}$. Control and CO-bubbled synaptosomes were preincubated at $30^{\circ} \mathrm{C}$ for 5 min. Incubation with either $\left[{ }^{3} \mathrm{H}\right]-$ Glu or $\left[{ }^{3} \mathrm{H}\right]-\mathrm{DA}$ was carried out at $30^{\circ} \mathrm{C}$ for $3 \mathrm{~min}$. The assay was stopped by the addition of ice-cold $0.32 \mathrm{M}$ sucrose and the synaptosomes were collected by rapid filtration through Whatmann GF/C filters. All determinations were performed in triplicates. Radioactivity in the filters was measured by liquid scintillation spectrometry (Pogun et al, 1994a, b).

\section{cGMP Assay}

cGMP levels in synaptosome suspensions were measured by radioimmunoassay kit (Amersham). Samples were deproteinized by adding acidic ethanol $(1 \mathrm{ml} 1 \mathrm{~N} \mathrm{HCl} / 100 \mathrm{ml}$ ethanol) and allowed to stand $10 \mathrm{~min}$ at room temperature before centrifuging. cGMP levels were expressed as pmol/g wet weight.

\section{$\mathrm{NO}_{2}^{-}+\mathrm{NO}_{3}^{-}$Assay}

To evaluate the effects of $\mathrm{CO}$ treatment on NO levels, total $\mathrm{NO}_{2}^{-}+\mathrm{NO}_{3}^{-}$levels were determined in synaptosomes prepared from rat brains. Total $\mathrm{NO}_{2}^{-}+\mathrm{NO}_{3}^{-}$levels were measured based on the reduction of nitrate to nitrite by nitrate reductase (EC 1.6.6.2) from Aspergillus sp. in the presence of NADPH. $\mathrm{NO}_{2}^{-}$levels were determined spectrophotometrically by the Griess reaction (Giovannoni et al, 1997; Taskiran et al, 1997). Sodium nitrate solutions were used for standard measurements. Total $\mathrm{NO}_{2}^{-}+\mathrm{NO}_{3}^{-}$levels were expressed as $\mu \mathrm{mol} / \mathrm{g}$ wet weight.

\section{Statistical Evaluation}

Results are given as the average of three values for each experiment and expressed as percent of control. SPPS Inc. V6.1 statistical package program was used for all statistical evaluations. Data were initially analyzed by multifactorial or one-way analyses of variance (ANOVA). Post hoc Bonferonni tests were applied for group comparisons. The difference between various treatments and control (100\%) values were determined by $t$-tests.

\section{RESULTS}

\section{Effect of Exogenous CO on $\left[{ }^{3} \mathrm{H}\right]-\mathrm{DA}$ and $\left[{ }^{3} \mathrm{H}\right]-\mathrm{Glu}$ Uptake}

CO treatment $(1,5$, and $10 \mathrm{~min})$ caused a time-dependent inhibition of both DA and Glu uptake (Figure 1). The 
Time-course and sex differences: Inhibition of [3H]-DA and [3H]-Glu uptake by $\mathrm{CO}$

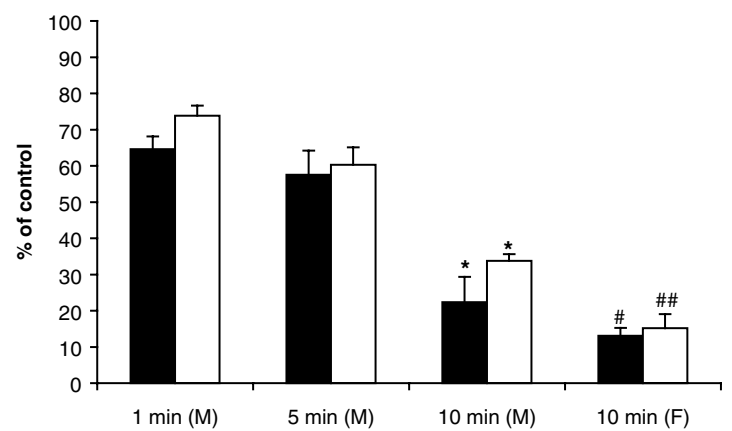

Figure I Time course of inhibition by $\mathrm{CO}$ treatment of $\left[{ }^{3} \mathrm{H}\right]-\mathrm{DA}$ and $\left.{ }^{3} \mathrm{H}\right]$-Glu uptake into synaptosomes in male rats and the sex difference observed after 10 min of $\mathrm{CO}$ exposure. Data are mean \pm SEM percent of control. M: male, F: female (*different from I and 5 min exposure, male rats $p<0.0001$; different from male rats after $10 \mathrm{~min}$ exposure, ${ }^{*} p<0.05$, $\# p<0.005)$.

difference between the groups was $\mathrm{F}_{(2,19)}=17,81, p<0.0001$ for DA and $\mathrm{F}_{(2,19)}=40,29, p<0.0001$ for Glu. The maximum effect of $\mathrm{CO}$ was observed at $10 \mathrm{~min}$, where inhibition was $77.66 \%$ for DA and $66.28 \%$ for Glu $(p<0.0001)$.

\section{Sex Difference in $\left[{ }^{3} \mathrm{H}\right]-\mathrm{DA}$ and $\left[{ }^{3} \mathrm{H}\right]$-Glu Uptake after CO Treatment}

In females both $\left[{ }^{3} \mathrm{H}\right]-\mathrm{DA}$ and $\left[{ }^{3} \mathrm{H}\right]$-Glu uptake were significantly decreased after $\mathrm{CO}$ treatment (86.95 and $84.83 \%$, for DA and Glu, respectively, $p<0.001$ ) (Figure 1). Two-way ANOVA of $\left[{ }^{3} \mathrm{H}\right]$-DA and $\left[{ }^{3} \mathrm{H}\right]$-Glu uptake, with sex (male $v s$ female) and CO treatment (CO present or absent) as factors, revealed a significant main effect of sex $\left(\mathrm{F}_{(1,28)}=10,39, p<0.005\right)$. Inhibition of $\left[{ }^{3} \mathrm{H}\right]-\mathrm{DA}$ and $\left[{ }^{3} \mathrm{H}\right]-$ Glu uptake was more pronounced in females than in males $(p<0.05$ and $p<0.005$, for DA and Glu, respectively).

\section{cGMP Levels after CO Treatment}

There was a regionally specific and significant sex difference with regard to cGMP levels in both control and CO-treated preparations. Two-way ANOVA was employed with sex (male $v s$ female) and treatment (CO present or absent) as the factors and cGMP levels as the dependent variable. ANOVA results revealed a significant main effect of sex $\left(\mathrm{F}_{(1,28)}=10,39, p<0.005\right)$ in the corpus striatum: cGMP levels were significantly higher in female rats than in male rats in both control and CO-treated groups $(p<0.05)$ (Figure 2). Furthermore, CO treatment elevated the cGMP levels in males but not in females in this region $(p<0.05)$. However, there was no difference between the groups in the hippocampus and no significant effect of $\mathrm{CO}$ treatment was observed (Figure 2).

\section{Total $\mathrm{NO}_{2}^{-}+\mathrm{NO}_{3}^{-}$Levels after $\mathrm{CO}$ Treatment}

There was no significant effect of $\mathrm{CO}$ treatment on total $\mathrm{NO}_{2}^{-}+\mathrm{NO}_{3}^{-}$levels in both corpus striatum and hippocam-

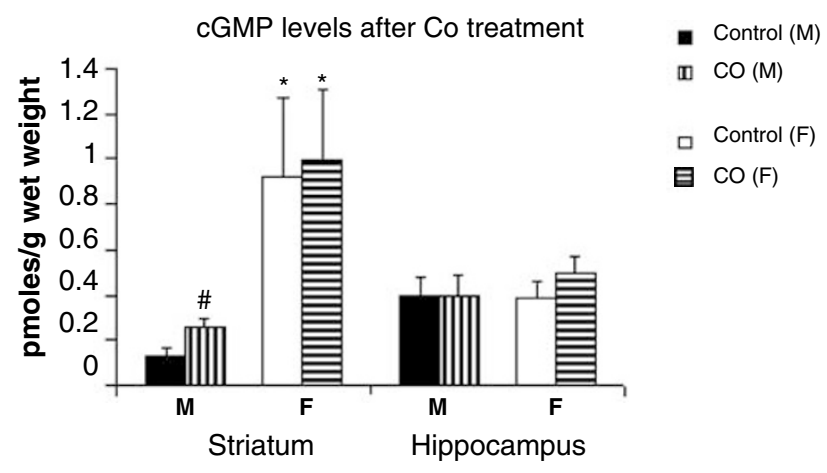

Figure 2 Striatal and hippocampal cGMP levels in female and male rats after CO treatment. Data are mean \pm SEM percent of control. M: male, F: female (striatum: "\#different from control, $p<0.05$; *different from male control and male CO-treated groups, $p<0.005$ ).

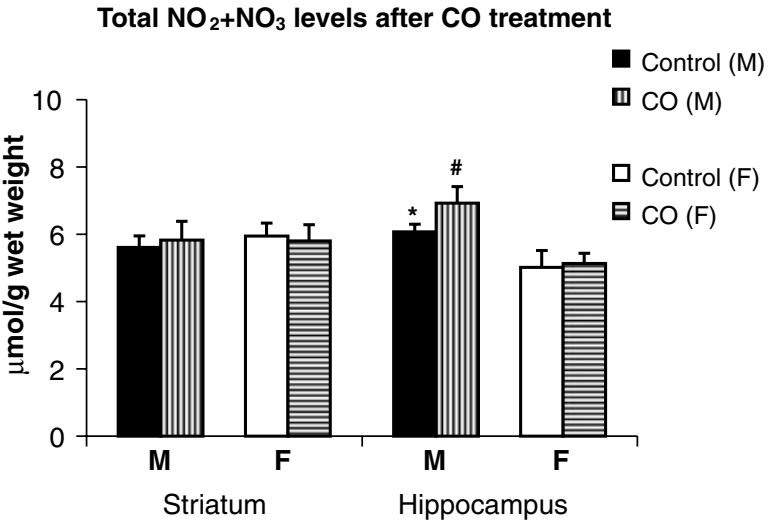

Figure 3 Striatal and hippocampal nitrate + nitrite levels in female and male rats after $\mathrm{CO}$ treatment. Data are mean \pm SEM percent of control. $M$ : male, F: female (hippocampus: *different from female control, $p<0.05$; \# different from female CO-treated group, $p<0.0 \mathrm{I}$ ).

pus (Figure 3), as assessed by the two-way ANOVA, with sex (male $v s$ female) and treatment (CO present or absent) as the factors and total $\mathrm{NO}_{2}^{-}+\mathrm{NO}_{3}^{-}$levels as the dependent variable. On the other hand, there was a significant main effect of sex in the hippocampus $\left(\mathrm{F}_{(1,28)}=12,67, p<0.001\right)$. NO metabolites were significantly higher in males than in females in both controls and CO-treated groups $(p<0.05$ and $p<0.01$, respectively) (Figure 3 ).

\section{Effect of CO Treatment on $\left[{ }^{3} \mathrm{H}\right]-\mathrm{DA}$ and $\left[{ }^{3} \mathrm{H}\right]$-Glu Uptake after In Vivo NOS Inhibition}

L-NA treatment increased both $\left[{ }^{3} \mathrm{H}\right]-\mathrm{DA}$ and $\left[{ }^{3} \mathrm{H}\right]-\mathrm{Glu}$ uptake compared to controls (104.37 and $108.87 \%$, respectively) (Figure 4). One-way ANOVA and post hoc Bonferonni test revealed significant differences between the groups $\left(\mathrm{F}_{(2,20)}=38,11, p<0.0001 ; \mathrm{F}_{(2,20)}=46,48, p<0.0001\right.$, for DA and Glu, respectively). CO treatment, with or without in vivo NOS inhibition, significantly decreased $\left[{ }^{3} \mathrm{H}\right]-\mathrm{DA}$ and $\left[{ }^{3} \mathrm{H}\right]$-Glu uptake compared to L-NA-treated group only $(p<0.0001)$ (Figure 4). There was no interaction between in vivo $\mathrm{L}-\mathrm{NA}$ treatment and ex vivo $\mathrm{CO}$ application, regarding DA and Glu uptake. 
Effects of $\mathrm{CO}$ treatment on [3H]-DA and [3H]-Glu $\square$ L-NA uptake after in vivo NOS inhibition

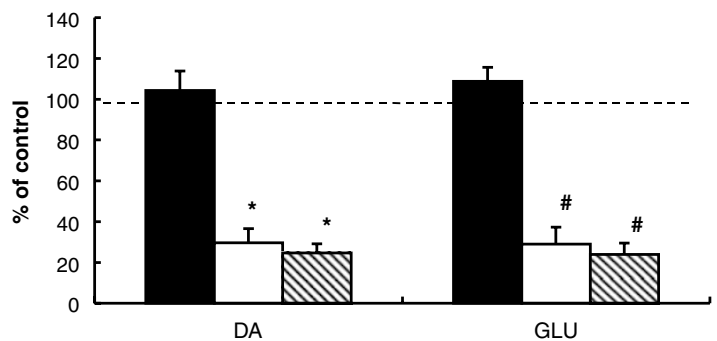

Figure 4 Effects of $\mathrm{CO}$ treatment on $\left[{ }^{3} \mathrm{H}\right]$-DA and $\left[{ }^{3} \mathrm{H}\right]$-Glu uptake following in vivo NOS inhibition (*different from in vivo NOS-inhibited group for $\left[{ }^{3} \mathrm{H}\right]$-DA, ${ }^{\#}$ different from in vivo NOS-inhibited group for $\left[{ }^{3} \mathrm{H}\right]$ Glu, $p<0.000$ I).

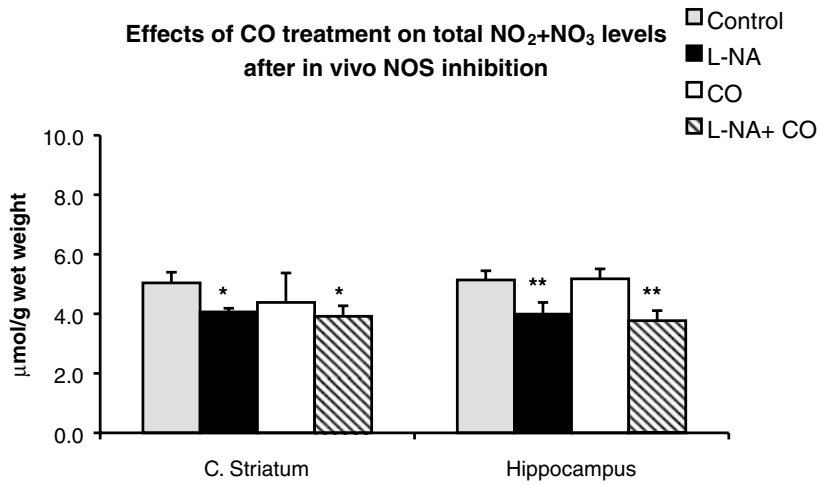

Figure 5 Effects of $\mathrm{CO}$ treatment on total nitrate and nitrite levels after in vivo NOS inhibition (different from control, $* p<0.05$ for c.striatum and *** $p<0.00$ I for hippocampus).

Total $\mathrm{NO}_{2}^{-}+\mathrm{NO}_{3}^{-}$Levels after $\mathrm{CO}$ Treatment of In Vivo NOS-Inhibited Rats

The total $\mathrm{NO}_{2}^{-}+\mathrm{NO}_{3}^{-}$levels after $\mathrm{CO}$ treatment in rats were evaluated with two-way ANOVA in the corpus striatum and hippocampus. L-NA and $\mathrm{CO}$ treatments (present or absent) were taken as factors and total $\mathrm{NO}_{2}^{-}+\mathrm{NO}_{3}^{-}$levels as the dependent variable. Total $\mathrm{NO}_{2}^{-}+\mathrm{NO}_{3}^{-}$levels were significantly lower in L-NA-treated groups than in controls $\left(\mathrm{F}_{(3,32)}=4,12, p<0.05\right.$ for corpus striatum and $\mathrm{F}_{(3,32)}=$ $13,83, p<0.001$ for hippocampus) (Figure 5). There was no significant effect of CO treatment alone.

\section{DISCUSSION}

Reuptake is the major mechanism that regulates synaptic levels of some neurotransmitters such as DA and Glu. The modulation of DA and Glu transporters not only influences the efficiency of synaptic transmission, but also mediates in neurotoxic processes. For example, while disturbed reuptake of Glu may underline some neurological disorders such as amyotrophic lateral sclerosis (ALS), inhibition of Glu uptake may also facilitate learning and memory processes (Rothstein, 1995). On the other hand, regulating dopaminergic neurotransmission by reuptake may affect reward systems or motor control with substantial influences in addictive or locomotor behavior, respectively (Taskiran et al, 2000).

Exposure to hypoxia and ischemic conditions increase extracellular levels of monoamine neurotransmitters in brain, and accumulation of DA and noradrenalin (NA) may influence the development of neuronal death during ischemia (Akiyama et al, 1991; Hiramatsu et al, 1996). Hiramatsu et al (1994) have reported significantly elevated levels of DA in striatal dialysates after $\mathrm{CO}$ exposure, while the levels of 3,4-dihydroxyphenylacetic acid (DOPAC) and homovanillic acid (HVA) decreased.

The most significant finding of the present study is the time-dependent inhibition of both DA and Glu uptake by $\mathrm{CO}$ treatment. The maximum inhibition was observed at 10 min of $\mathrm{CO}$ treatment (Figure 1); the inhibition was also temperature dependent and was not observed at $0^{\circ} \mathrm{C}$ (data not shown). In agreement with our findings, Pogun et al have shown time-, temperature- and dose-dependent inhibition of DA and Glu uptake by the NO generator sodium nitroprusside (SNP) in synaptosomes prepared from rat brain, in a regionally selective manner (Pogun et al, 1994a, b; Pogun and Kuhar, 1994). DA and Glu uptake mechanism is an ATP-dependent process, and hypoxia causes ATP depletion within 5 min (Hansen, 1985). Indeed, CO binds to cytochrome $c$ oxidase in the brain, resulting in a decreased rate of mitochondrial energy production (Piantadosi et al, 1995). Although the mechanism is not documented yet, one possible explanation of the inhibition of transport by CO may be reduced ATP production.

Sex is an important factor that influences neurotransmitter sytems, and the vulnerability of the male and female brain to ischemia and neuropathological conditions vary (Ferris et al, 1995; Meyer et al, 1998). In the present study, CO decreased DA and Glu uptake into synaptosomes prepared from both female and male rat brains. However, the inhibition was higher in female than in male rats (Figure 1). This finding suggests greater sensitivity of female rats to CO toxicity or to transporter modulation than males. However, CO toxicity may have other effects beyond transporter modulation, which influence vulnerability. A recent case report suggests differential susceptibility of the male and female brain to $\mathrm{CO}$ poisoning: A married couple was exposed $\mathrm{CO}$ and 1 month later only the husband developed Parkinsonism, a common neurological sequela of CO poisoning; the initial white matter damage studied by MRS was more severe in the husband than in the wife (Sohn et al, 2000).

Like NO, CO binds to the iron of the heme moiety in sGC to activate the enzyme. HO-sGC colocalization has been demonstrated in many brain regions and this colocalization is more pronounced than that of NOS-sGC. However, despite this high colocalization, the activation of sGC by CO is only about $1 \%$ of the activation of sGC by NO (Burstyn et al, 1995; Stone and Marletta, 1994). Furthermore, while the effect of CO on cGMP induction is reported in the cerebellum, no significant elevation in cGMP formation was observed in cortical regions (Laitinen et al, 1997). Although the activation of isolated sGC with $\mathrm{CO}$ is much weaker than with $\mathrm{NO}, \mathrm{CO}$ can be a powerful activator in stimulating cGMP in the presence of an indazole; Friebe et al (1998) have shown a 100-fold increase in the affinity of 
$\mathrm{CO}$ to $\mathrm{sGC}$ in the presence of YC-1, a benzylindazole derivative. On the other hand, there are studies demonstrating that $\mathrm{CO}$ may have effects independent of cGMP. For example, in a patch clamp study, Wang et al (1997) have shown that exogenous $\mathrm{CO}$ application can activate the $238 \mathrm{pSK}_{\mathrm{Ca}}$ channel independent of cGMP. Similarly, Kaide et al (2001) demonstrated the cGMP-independent activation of the $105 \mathrm{pSK}_{\mathrm{Ca}}$ channel by CO. These results provide evidence that other routes may be involved in $\mathrm{CO}$ action than cGMP.

Recent observations have suggested that $\mathrm{NO}$ can function as a very effective and short-lived stimulator of cGMP production, while CO produces long-term effects on cGMP levels because of its chemical stability (Zhuo et al, 1993). In our study, exogenous CO application had an effect only in the striatum and only in the male rats: of the two brain regions studied, CO increased cGMP levels in the striatum, but not in the hippocampus (Figure 2). In female rats, CO was without any effect on cGMP levels in either brain region. Basal cGMP levels were significantly higher in the striatum of female rats than males, while no sex difference was observed in the hippocampus. Palmon et al (1998) reported sex differences in basal cGMP levels, with higher levels in females. Furthermore, a dose-dependent increase in cGMP levels by estrogen was observed, however most significantly in the hippocampus.

Several studies have reported the interactions between CO- and NO-generating systems (Zhuo et al, 1993; Maines, 1997; Snyder et al, 1998). Since NOS is a hemoprotein, CO is able to bind to the existing NOS and inactivate the molecule. Conversely, NO could modulate HO-2 activity through free radical attack on - SH groups on HO-2 (Verma et al, 1993; Maines, 1997; Juckett et al, 1998). Ischiropoulos et al (1996) have found that $\mathrm{CO}$ exposure leads to the perivascular accumulation of nitrotyrosine, a marker of peroxynitrite $\left(\mathrm{OONO}^{-}\right)$production. Furthermore, Thorup et al (1999) have shown that picomolar concentrations of $\mathrm{CO}$, in renal resistance arteries from rats, facilitate the release of NO from a large intracellular pool, whereas micromolar concentrations of $\mathrm{CO}$ inhibit NOS activity and NO generation. Our results, in accordance with our previous findings, showed that while $\mathrm{NO}_{2}^{-}+\mathrm{NO}_{3}^{-}$levels were higher in the male hippocampus than the female (Taskiran et al, 1997), CO treatment had no effect on total $\mathrm{NO}_{2}^{-}+\mathrm{NO}_{3}^{-}$ levels both in the male and female rat brain. Although this finding is not consistent with some of the previous studies mentioned above, it may be explained by the observation of Stamler and Piantadosi (1996). According to their hypothesis, CO may competitively displace NO by binding to heme irons in proteins and induce $\mathrm{ONOO}^{-}$production by disrupting mitochondrial electron transport. The study by Stamler and Piantadosi suggests that CO may be replacing NO and thereby causing peroxynitrite formation without affecting NOS. In the endothelium, CO may be competing for the intracellular binding sites of NO (hemoproteins) to increase steady-state NO levels and peroxynitrite without altering arginine transport or NOS activity (Thom et al, 1997, 1999). As Cary and Marletta (2001) discuss in a recent review, extensive research is needed before we can reach a conclusion about $\mathrm{CO}$ as a signaling molecule and its interactions with the nitrergic systems.

In our previous study, we have reported the facilitation of DA and Glu uptake in in vivo NOS-inhibited rats (Koylu et al, 1998). The present study confirmed our results. L-NA treatment increased the DA and Glu uptake compared to control levels. CO treatment with or without sytemic L-NA injection inhibited both DA and Glu uptake suggesting that $\mathrm{CO}$ action is not dependent on the NO system. Although CO and NO seem to share similar biological properties, they can regulate the transporter functions through different mechanisms.

In conclusion, the present study provides evidence for the inhibition of DA and Glu reuptake in a time-, dose-, and temperature-dependent manner in the rat striatum and hippocampus. The inhibition observed is sexually dimorphic and independent of the NOS activity. These results suggest that $\mathrm{CO}$ may act as a modulator of synaptic transmission.

\section{ACKNOWLEDGMENTS}

This study was supported by grants from the Ege University Research Fund 97/BIL/010, 99/TIP/005, and from the Scientific and Technical Research Council of Turkey (TUBITAK) SBAG-U/15-1.

\section{REFERENCES}

Akiyama Y, Koshimura K, Ohue T, Lee K, Miwa S, Yamagata S (1991). Effects of hypoxia on the activity of the dopaminergic neuron system in the rat striatum as studied by in vivo brain microdialysis. J Neurochem 57: 997-1002.

Brune B, Schmidt KU, Ullrich V (1990). Activation of soluble guanylate cyclase by carbon monoxide and inhibition by superoxide anion. Eur J Biochem 192: 683-688.

Burstyn JN, Yu AE, Dierks E, Hawkins BK, Dawson JH (1995). Studies of the heme coordination and ligand binding properties of soluble guanylyl cyclase (sGC): characterization of $\mathrm{Fe}(\mathrm{II}) \mathrm{sGC}$ and $\mathrm{Fe}(\mathrm{II}) \mathrm{sGC}(\mathrm{CO})$ by electronic absorption and magnetic circular dichroism spectroscopies and failure of $\mathrm{CO}$ to activate the enzyme. Biochemistry 34: 5896-5903.

Cary S, Marletta MA (2001). The case of CO signalling: why the jury is still out. J Clin Invest 107: 1071-1073.

Ewing JF, Maines MD (1997). Histochemical localization of heme oxygenase-2 protein and mRNA expression in rat brain. Brain Res Brain Res Protoc 1: 165-174.

Ferris DC, Kume-Kick J, Russo-Menna I, Rice ME (1995). Gender differences in cerebral ascorbate levels and ascorbate loss in ischemia. Neuroreport 6: 1485-1489.

Forman LJ, Liu P, Nagele RG, Yin K, Wong PY (1998). Augmentation of nitric oxide, superoxide, and peroxynitrite production during cerebral ischemia and reperfusion in the rat. Neurochem Res 23: 141-148.

Friebe A, Mullershausen F, Smolenski A, Walter U, Schultz G, Koesling D (1998). YC-1 potentiates nitric oxide- and carbon monoxide-induced cyclic GMP effects in human platelets. Mol Pharmacol 54: 962-967.

Galbraith R (1999). Heme oxygenase: who needs it? Proc Soc Exp Biol Med 222: 299-305.

Giovannoni G, Land JM, Keir G, Thompson EJ, Heales SJ (1997). Adaptation of the nitrate reductase and Griess reaction methods for the measurement of serum nitrate plus nitrite levels. Ann Clin Biochem 34: 193-198.

Hansen AJ (1985). Effect of anoxia on ion distribution in the brain. Physiol Rev 65: 101-148.

Hiramatsu M, Kameyama T, Nabeshima T (1996). Carbon monoxide-induced impairment of learning, memory and 
neuronal dysfunction. In: Penney DG (ed). Carbon Monoxide. CRC Press: Boca Raton, FL. pp 187-204.

Hiramatsu M, Yokoyama S, Nabeshima T, Kameyama T (1994). Changes in concentrations of dopamine, serotonin, and their metabolites induced by carbon monoxide (CO) in the rat striatum as determined by in vivo microdialysis. Pharmacol Biochem Behav 48: 9-15.

Ingi T, Cheng J, Ronnett GV (1996a). Carbon monoxide: an endogenous modulator of the nitric oxide-cyclic GMP signaling system. Neuron 16: 835-842.

Ingi T, Chiang G, Ronnett GV (1996b). The regulation of heme turnover and carbon monoxide biosynthesis in cultured primary rat olfactory receptor neurons. J Neurosci 16: 5621-5628.

Ischiropoulos H, Beers MF, Ohnishi ST, Fisher D, Garner SE, Thom SR (1996). Nitric oxide production and perivascular nitration in brain after carbon monoxide poisoning in the rat. J Clin Invest 97: 2260-2267.

Johnson RA, Johnson FK (2000). The effects of carbon monoxide as a neurotransmitter. Curr Opin Neurol 13: 709-713.

Juckett M, Zheng Y, Yuan H, Pastor T, Antholine W, Weber M (1998). Heme and the endothelium. Effects of nitric oxide on catalytic iron and heme degradation by heme oxygenase. J Biol Chem 273: 23388-23397.

Kaide JI, Zhang F, Wei Y, Jiang H, Yu C, Wang WH (2001). Carbon monoxide of vascular origin attenuates the sensitivity of renal arterial vessels to vasoconstrictors. J Clin Invest 107: 1163-1171.

Koylu EO, Demirgören S, Taskiran D, Kuhar MJ, Pogun S (1998). Effects of nitric oxide synthase (NOS) inhibition on glutamate and dopamine transport. http://www.mcmaster.ca/inabis98/ index.html.

Kuhar MJ (1997). Dopamine transporter: function and imaging. In: Pogun S (ed). Neurotransmitter Release and Uptake. SpringerVerlag: Berlin. pp 221-229.

Kuhar MJ, Couceyro PR, Lambert PD (1999). Catecholamines. In: Siegel GJ, Agranoff BW, Albers RW, Fisher SK Uhler MD (eds). Basic Neurochemistry: Molecular, Cellular and Medical Aspects. Lippincott-Raven, Philadelphia, PA. pp 243-261.

Kutty RK, Maines MD (1981). Purification and characterization of biliverdin reductase from rat liver. $J$ Biol Chem 256: 3956-3962.

Kutty RK, Maines MD (1982). Oxidation of heme $c$ derivatives by purified heme oxygenase. Evidence for the presence of one molecular species of heme oxygenase in the rat liver. J Biol Chem 257: 9944-9952.

Laitinen KS, Salovaara K, Severgnini S, Laitinen JT (1997). Regulation of cylic GMP levels in the rat frontal cortex in vivo: effects of exogenous carbon monoxide and phosphodiesterase inhibition. Brain Res 755: 272-278.

Magnusson S, Ekstrom TJ, Elmer E, Kanje M, Ny L, Alm P (2000). Heme oxygenase-1, heme oxygenase- 2 and biliverdin reductase in peripheral ganglia from rat, expression and plasticity. Neuroscience 95: 821-829.

Maines MD (1988). Heme oxygenase: function, multiplicity, regulatory mechanisms, and clinical applications. Faseb $\mathrm{J}$ 2: 2557-2568.

Maines MD (1997). The heme oxygenase system: a regulator of second messenger gases. Annu Rev Pharmacol Toxicol 37: 517-554.

Meyer JS, Terayama Y, Konno S, Akiyama H, Margishvili GM, Mortel KF (1998). Risk factors for cerebral degenerative changes and dementia. Eur Neurol 39: 7-16.

Palmon SC, Williams MJ, Littleton-Kearney MT, Traystman RJ, Kosk-Kosicka D, Hurn PD (1998). Estrogen increases cGMP in selected brain regions and in cerebral microvessels. J Cereb Blood Flow Metab 18: 1248-1252.

Piantadosi CA (1996). Toxicity of carbon monoxide: hemoglobin vs histotoxic mechanisims. In: Penney DG (ed). Carbon Monoxide. CRC Press: Boca Raton, FL. pp 163-180.

Piantadosi CA, Tatro L, Zhang J (1995). Hydroxyl radical production in the brain after CO hypoxia in rats. Free Radical Biol Med 18: 603-609.

Pogun S (1997). Modulation of neurotransmitter uptake. In: Pogun S (ed). Neurotransmitter Release and Uptake. Springer-Verlag: Berlin, Heidelberg. pp 283-299.

Pogun S, Baumann MH, Kuhar MJ (1994a). Nitric Oxide Inhibits [3H]Dopamine uptake. 641: 83-91.

Pogun S, Dawson V, Kuhar MJ (1994b). Nitric oxide inhibits 3Hglutamate transport in synaptosomes. Synapse 18: 21-26.

Pogun S, Kuhar MJ (1994). Regulation of neurotransmitter reuptake by nitric oxide. Ann NY Acad Sci 738: 305-315.

Rothstein JD (1995). Excitotoxic mechanisms in the pathogenesis of amyotrophic lateral sclerosis. Adv Neurol 68: 7-20.

Snyder SH, Jaffrey SR, Zakhary R (1998). Nitric oxide and carbon monoxide: parallel roles as neural messengers. Brain Res Brain Res Rev 26: 167-175.

Sohn YH, Jeong Y, Kim HS, Im JH, Kim JS (2000). The brain lesion responsible for Parkinsonism after carbon monoxide poisoning. Arch Neurol 57: 1214-1218.

Stamler JS, Piantadosi CA (1996). O = O NO: it's CO. J Clin Invest 97: 2165-2166.

Stone JR, Marletta MA (1994). Soluble guanylate cyclase from bovine lung: activation with nitric oxide and carbon monoxide and spectral characterization of the ferrous and ferric states. Biochemistry 33: 5636-5640.

Tanaka K (2000). Functions of glutamate transporters in the brain. Neurosci Res 37: 15-19.

Taskiran D, Kutay FZ, Sozmen E, Pogun S (1997). Sex differences in nitrite/nitrate levels and antioxidant defense in rat brain. Neuroreport 8: 881-884.

Taskiran D, Sagduyu A, Yuceyar N, Kutay FZ, Pogun S (2000). Increased cerebrospinal fluid and serum nitrite and nitrate levels in amyotrophic lateral sclerosis. Int J Neurosci 101: 65-72.

Thom SR, Fisher D, Xu YA, Garner S, Ischiropoulos H (1999). Role of nitric oxide-derived oxidants in vascular injury from carbon monoxide in the rat. Am J Physiol 276: H984-H992.

Thom SR, Xu YA, Ischiropoulos H (1997). Vascular endothelial cells generate peroxynitrite in response to carbon monoxide exposure. Chem Res Toxicol 10: 1023-1031.

Thorup C, Jones CL, Gross SS, Moore LC, Goligorsky MS (1999). Carbon monoxide induces vasodilation and nitric oxide release but suppresses endothelial NOS. Am J Physiol 277: F882-F889.

Verma A, Hirsch DJ, Glatt CE, Ronnett GV, Snyder SH (1993). Carbon monoxide: a putative neural messenger. Science 259: 381-384.

Wang R, Wu L, Wang Z (1997). The direct effect of carbon monoxide on $\mathrm{K}_{\mathrm{Ca}}$ channels in vascular smooth muscle cells. Pflugers Arch 434: 285-291.

Yilmaz O, Kanit L, Okur BE, London ED, Pogun S (2000). Nitric oxide synthetase inhibition hinders facilitation of active avoidance learning by niotine in rats. Behav Pharmacol 11: 505-510.

Zhuo M, Small SA, Kandel ER, Hawkins RD (1993). Nitric oxide and carbon monoxide produce activity-dependent longterm synaptic enhancement in hippocampus. Science 260: 1946-1950. 